\title{
Chelator in Environmentally-exposed Poor Detoxifiers: An Adjuvant Hepatoprotective Treatment for Poly-drug Users?
}

Makida $\mathrm{Y}^{1,7}$, He $\mathrm{F}^{2}$, Mohania $\mathrm{D}^{3}$, Balieiro-Neto $\mathrm{G}^{4}$, Alagozlu $\mathrm{H}^{5}$, Pathak $\mathrm{S}^{6}$, Naito $\mathrm{Y}^{1}$, Lorenzetti $\mathrm{A}^{7}$, Takadanohara $\mathrm{H}^{1}$, Cervi $\mathrm{J}^{1}$ and $\mathrm{Marotta}^{7,8 *}$

${ }^{1}$ Medical Corporation Seyukai and Outpatients Clinic, Nagoya, Japan

${ }^{2}$ Department of Nutrition and Food Hygiene, West China School of Public Health, Sichuan University, China

${ }^{3}$ Department of Research, Sir Ganga Ram Hospital, Rajinder Nagar, New Delhi, India

${ }^{4}$ Department of Agriculture and Food Supply, Sao Paulo, Brazil

${ }^{5}$ Gastroenterology Department, Medical Park Ankara Hospital, Ankara, Turkey

${ }^{6}$ Faculty of Allied Health Sciences, Chettinad Hospital and Research, Chennai, India

${ }^{7}$ ReGenera Research Group for Aging-Intervention, Milano, Italy

${ }^{8}$ Milano Medical-Healthy Aging Unit by Genomics and Biotechnology, Milano, Italy

\begin{abstract}
Glutathione-S-Transferase (GST) genes, including GSTT1, GSTP1, and GSTM1, play a major role in detoxification and metabolism of xenobiotics. The aim of the present study was to test an orally bioavailable GSH-based compound in poor detoxifier subjects regarding their oxidative stress, ammonia metabolism and heavy metal clearance. Eligibility was established with a telephone questionnaire followed by a clinical examination to obtain height, weight, blood pressure and screening blood chemistry and GSTM-1 gene test. Seventy-five GSTM1-null, non-smoking healthy individuals were introduced in the study who were teetotallers or were using a maximum of $20 \mathrm{~g}$ alcohol/day men $(n=47)$ and women $(n=28)$ aged 38-69 years (mean: 49.7) with body-mass index ranging from 22 to $29 \mathrm{~kg} / \mathrm{m}^{2}$ ) participated in the study. All enrolled participants were free from acute or chronic diseases and did not eat a diet or take medications that might interfere with outcome markers namely antioxidant supplements, high intake of dietary polyphenols including coffee, grapefruit juice or anti-inflammatory medications. Subjects were divided in 3 groups ( 25 subjects each): a) Given an oral bioabsorbable glutathione-based compound added with selenium, L-cysteine and vitamin C (GLU-9599, Named Research Co., Lesmo, Italy) at the dosage of 1 tab a day for two months; b) $600 \mathrm{mg}$ of glutathione in 250 saline, given intravenously over $90 \mathrm{~min}$, twice a week for 2 months; and c) Given $3 \mathrm{~g}$ a day of a strong cation-exchange oral chelator consisting of a mixture of chabasite-phillipsite for two months. Dietary questionnaire was administered to all subjects. Either at baseline, at one month or at the end of the study the following parameters were tested: erythrocytes (RBC) level of GSH/GSSG and Glutathione Peroxidise (GPx), urinary 8-OHdG, $24 \mathrm{~h}$ urinary measurement of main heavy metals, faecal metals, ammonia and oxidative stress. GLU-9599 showed to significantly lower either RBC oxidative stress or urinary $8-\mathrm{OHdG}$ as compared to either IV glutathione or oral chelator $(p<0.01)$. There was a significant correlation between urinary $8-\mathrm{OHdG}$ and overall heavy metal excretion $(r: 0.58, p<0.005)$ but no correlation occurred with RBC oxidative stress. Few subjects with fatty liver and abnormal transaminases improved their value during treatment with GLU-9599. Only oral chelator was effective in significantly lower faecal metals, ammonia and faecal oxidative stress $(p<0.005)$. There was a not significant trend increase of mercury faecal excretion and GLU-9599. Overall, it would appear that in poor-detoxifier (GSTM1-null genotype) subjects, an effective orally-absorbable stabilised-glutathione can efficiently restore antioxidant defences in view of a potential wider application as an integrative adjuvant co-treatment in patients environmentally-exposed and also under pharmacological burden. Effective heavy metal clearance remains a still unresolved issue which may benefit from the rational addition of high cation-exchange oral chelators with a likely association with viable glutathione supplements too.
\end{abstract}

Keywords: Hepatoprotective; Carcinogenic; Antioxidant; Genomic instability; Biomarker

\section{Introduction}

The liver is specifically structured to be an organ endowed with drug-metabolizing enzymes, drug transporters and drug clearance mechanisms. Most xenobiotics compounds, including therapeutic drugs, enter the body by absorption from the gastrointestinal tract [1]. Moreover, as research progresses, harms more subtle than acute poisoning from heavy metals are seen at lower burdens of such pollutants [2-5]. Toxic metals are ubiquitous in our environment and human body at higher than historical levels [6]. A growing number of studies are highlighting the detrimental role of heavy metals in the environment and genomic instability by affecting epigenetic modification and DNA repair mechanisms [7]. Moreover, it has been shown that such heavy metals burden, as well as other pollutants, triggers oxidative phenomena which, on their turn, may help maintaining damaging cellular mechanisms. Indeed, $8-\mathrm{OHdG}$ has been proposed as a genotoxic biomarker in aluminium- and chromate-exposed subjects [8-10]. Environmental pollutants are able to alter epigenetic regulatory characteristics such as methylation state, nucleosome position, local and regional CpG density, transcription factor binding sites and microRNA expression. However, the mechanisms of such environmentally associated epigenetic alteration remains to be fully elucidated as yet and it is very likely that different quali/quantitative modalities of exposure, occurring either in childhood or in adulthood,

*Corresponding author: Marotta F, ReGenera Research Group for Aging Intervention, Milano, Italy \& Milano Medical-Healthy Aging Unit by Genomics and Biotechnology, Milano, Italy, Tel: 39024077243; E-mail: fmarchimede@libero.it

Received August 28, 2016; Accepted September 12, 2016; Published September 16, 2016

Citation: Makida Y, He F, Mohania D, Balieiro-Neto G, Alagozlu H, et al. (2016) Effect of a Novel GSH-based Compound and Chabasite-phillipsite-based Chelator in Environmentally-exposed Poor Detoxifiers: An Adjuvant Hepatoprotective Treatment for Poly-drug Users? Metabolomics (Los Angel) 6: 185. doi: 10.4172/2153-0769.1000185

Copyright: @ 2016 Makida Y, et al. This is an open-access article distributed under the terms of the Creative Commons Attribution License, which permits unrestricted use, distribution, and reproduction in any medium, provided the original author and source are credited. 
activate different mechanisms which contribute to distinct epigenetic modifications. GSH transferases detoxify not only electrophiles derived from xenobiotics, but also endogenous electrophiles which are usually the end hydroperoxides products of lipids and DNA.

Polymorphisms in GST genes may epigenomically modify the activity of key enzymes involved with the preservation of cellular Glutathione (GSH) concentration. As a matter of fact, it is well-known that Glutathione S-Transferase mu (GSTM1) and theta 1 (GSTT1) exert relevant roles in detoxification of xenobiotics and the latter is found to be null in about $50 \%$ of Caucasians $[11,12]$. Studies have shown that polymorphisms in GST genes, particularly GSTM1, may be associated with increased susceptibility to lead and mercury toxicity, affect the metabolism of methyl-mercury and environmental pollutants, as overall [13-15]. Interestingly, GSTM1 null-genotype has been found to be more associated to lower vitamin $\mathrm{C}$ and the authors have suggested that antioxidants supplementation should be considered for these subjects with unfavourable genetic makeup, especially if with altered markers of oxidative stress [16].

Within the overall understanding of lowering the toxic burden of the liver, one cannot do without considering also the most important endogenous factor, i.e., ammonia. While this metabolite is certainly noxious to patients with liver disease, recent studies have shown that it would be advisable to lower the ammoniogenic gut metabolisms also in healthy individuals and in those practicing sport [17-19]. Cytosolic Glutathione S-Transferase (GST) enzymes play a key role in biological detoxification processes but two most important human isoenzymes, i.e., GSTT1-1 and GSTM1-1, are genetically deleted in a high percentage of the human population GSTM1-1 is particularly relevant in the deactivation of carcinogenic intermediates and of reactive oxygen species involved in cellular processes of ageing per se, inflammation and degenerative diseases. Moreover, it is likely that this deletion, possibly associated with other gene traits, affect drug metabolism in human organisms, thing of raising concern with the increase of elderly population and poly-pharmacological regimes they are often exposed to [20]. The aim of our study was to test an optimized orobuccal release formulation tablet containing pure stabilized GSH compound in poordetoxyfier subjects as classified being GSTM1-null genotype.

\section{Materials and Methods}

Eligibility was established with a telephone questionnaire followed by a clinical examination to obtain height, weight, blood pressure and screening blood chemistry and GSTM-1 gene test.

\section{Pre-recruitment gene test}

For analysis of GSTM1 genotype, whole blood was collected in EDTA lavender top vacutainers for each participant, blood components were centrifuged and separated and peripheral blood leukocytes were obtained before enrolling, as decision criteria. The GSTM1 genotype was detected using a multiplex Polymerase Chain Reaction (PCR) reaction. Genomic DNA was isolated using the Gentra Puregene Kit (Qiagen, China Co., Ltd) in accordance with the manufacturer's protocol. 80-100 ng of DNA was amplified in a total volume of $25 \mathrm{ml}$ reaction containing $20 \mathrm{mmol} / \mathrm{L}$ Tris- $\mathrm{HCl} ; 50 \mathrm{mmol} / \mathrm{L} \mathrm{KCl} ; 1.5 \mathrm{mmol} / \mathrm{L}$ $\mathrm{MgCl}_{2} ; 2 \mathrm{mmol} / \mathrm{L}$ of each deoxynucleotide triphosphate; $1 \mathrm{pmol}$ of each primer; and $1.25 \mathrm{U}$ of AmpliTaq DNA polymerase. PCR was carried out in a termocycler (ThermoFisher, Tokyo, Japan), after 5 min of pretreatment at $94^{\circ} \mathrm{C}, 30$ cycles of $1 \mathrm{~min}$ at $94^{\circ} \mathrm{C}, 1 \mathrm{~min}$ at $59^{\circ} \mathrm{C}$ and 30 $\mathrm{s}$ at $72^{\circ} \mathrm{C}$, followed by $5 \mathrm{~min}$ at $72^{\circ} \mathrm{C}$. The PCR products were analyzed by electrophoresis on $10 \%$ acrylamide gel and detected by a non-radioisotopic technique using a commercially available silver staining method.
Briefly, the absence of a $230 \mathrm{bp}$ product in the electrophoretic profile indicates homozygous deficiency for the GSTM1 gene. As a quality control, a beta-globin amplicon of $280 \mathrm{bp}$ was included in the assay. A fragment of 312 bp related to a nonpolymorphic fragment of the CYP1A1 gene was used as an internal control in all reactions. The ABI 7900HT Sequence Detection System (Applied Biosystems, USA) was used for ascertainment of the genotypes.

\section{Study design}

Seventy-five GSTM1-null, healthy, non smoking teetotaller or using a maximum of $20 \mathrm{~g}$ alcohol/day men $(\mathrm{n}=47)$ and women $(\mathrm{n}=28)$ aged $38-69$ years $($ mean $=49.7)$ with body-mass index ranging from 22 to $29 \mathrm{~kg} / \mathrm{m}^{2}$ participated in the study. All enrolled participants were free from acute or chronic diseases and did not consume antioxidant or other supplements such high intake of dietary polyphenols including coffee, grapefruit juice or anti-inflammatory medications. Subjects were divided in 3 groups ( 25 subjects each): a) Given an oral bioavailable glutathione-based compound added with selenium, L-cysteine and vitamin C (GLU-9599, (content per $100 \mathrm{mg}$ : GSH $36 \mathrm{mg}$ in a patented orally-bioavailable form, vitamin C $6 \mathrm{mg}$, L-cystein 7,4 mg, selenium 8 mcg, Named Research Co., Lesmo, Italy) at the dosage of $1 \mathrm{tab}$ a day for two months; b) $600 \mathrm{mg}$ of glutathione in $250 \mathrm{ml}$ saline, given intravenously over $90 \mathrm{~min}$ with a pump-syringe, twice a week for 2 months; and c) Given 3 gr a day of an oral chelator consisting of a mixture of polyols, chabasite-phillipsite and organic ascorbate (Novagenics-SOL ltd, HongKong), for two months.

\section{Dietary questionnaire}

As for nutritional assessment tool over the past month and during the study period, it was used the web-based version of the National Institutes of Health Diet History Questionnaire (NIHDHQ). This consists of a food frequency questionnaire listing 124 food items and portion sizes. This tool has been shown to provide a fairly reliable nutrient estimate and fair consistency and validity [21]. A great deal of attention was paid as for advising patients not to change their dietary habit during the observation period. In particular, they were warned not to increase fish or shell fish or algae intake and no food supplement was allowed.

\section{Ethics approval and consent}

This work was ethically approved by the internal review board (ReGenera Research Association for no-profit Studies in Aging Intervention, protocol GLU-9599-24/2014) according to the principles of the Helsinki Declaration. A written consent was obtained from each individual, according to the guidelines of the board.

\section{Samples collection and storage}

After an overnight fast, venous blood samples were taken and put into a dry tube for serum, a citrate containing tube, while an EDTA-containing tube for plasma was used for clinical chemistry analyses. The tubes were centrifuged at $3500 \mathrm{rpm}$ for 15 minutes at room temperature. Plasma was separated and stored at $-80^{\circ} \mathrm{C}$ until required for analysis.

On the examination day, blood samples were taken for routine testing (glucose, transaminases, haemoglobin, urea, creatinine, electrolytes) by automated standardized procedures (Hitachi 911 using commercial kits) and for further studies as described below. Blood, faecal and urine samples were taken at entry, at 1 and at 2 months.

\section{Biochemical Assays}

Routine biochemistry performed by an autoanalyser (CLS-B201, Landcom Medical Science \& Technology Co., Ltd., Xian, China). 
Citation: Makida Y, He F, Mohania D, Balieiro-Neto G, Alagozlu H, et al. (2016) Effect of a Novel GSH-based Compound and Chabasite-phillipsitebased Chelator in Environmentally-exposed Poor Detoxifiers: An Adjuvant Hepatoprotective Treatment for Poly-drug Users? Metabolomics (Los Angel) 6: 185. doi: 10.4172/2153-0769.1000185

Page 3 of 7

\section{Measurement of glutathione status in erythrocytes}

Fasting peripheral blood $(0.5 \mathrm{~mL})$ samples were obtained from subjects in the morning were centrifuged at $1000 \mathrm{~g}$ for $10 \mathrm{~min}$ and put into heparinized tubes. The blood was diluted with equal volume of $\mathrm{Ca}^{++}$and $\mathrm{Mg}^{++}$free Dulbecco's Phosphate Buffered Saline (PBS). Erythrocytes were separated from plasma and buffy coat and washed three times with 10 vol of phosphate-buffered saline (PBS, pH 7.4) to obtain erythrocyte sediments. Erythrocytes were then fractionated by Percoll discontinuous density gradient/centrifugation. Glutathione metabolites were measured in RBC using a spectrophotometric methodology [22]. Briefly, samples were precipitated with ice-cold metaphosphoric acid and kept at $4^{\circ} \mathrm{C}$ to be subsequently centrifuged for $10 \mathrm{~min}$ at $1200 \mathrm{~g}$ for preparing samles for GSH and GSSG measurements. As for glutathione peroxidase activity the extraction mixture consisted of $50 \mathrm{mM}$ potassium phosphate buffer ( $\mathrm{pH} 7), 1 \mathrm{mM}$ EDTA, $1 \mathrm{mM} \mathrm{NaN}_{3}, 0.2 \mathrm{mM} \mathrm{NADPH}, 1 \mathrm{EU} / \mathrm{ml}$ GSSG reductase, 1 $\mathrm{mM} \mathrm{GSH}, 1.5 \mathrm{mM}$ cumene hydroperoxide or $0.25 \mathrm{mM} \mathrm{H}_{2} \mathrm{O}_{2}$ in a total volume of $1 \mathrm{ml}$. Red-cell lysate was added to $0.8 \mathrm{ml}$ of the mixture and incubated for $5 \mathrm{~min}$ at room temperature before adding $0.1 \mathrm{ml}$ peroxide solution to trigger reaction. Supernatants of the above procedures were retrieved and split and absorbance at $340 \mathrm{~nm}$ was recorded for $5 \mathrm{~min}$. In particular, the GPx activity was calculated from the slope of these lines as mol NADPH oxidized per minute. Blank reactions were subtracted from each assay [23].

\section{Urine collection}

For heavy metals evaluation, total 24 h-urinary collection volume was recorded and aliquots $(100 \mathrm{~mL})$ were treated with $2 \mathrm{~mL}$ of $90 \%$ pure $\mathrm{HNO}^{3}$ and stored at $-20^{\circ} \mathrm{C}$ until assay. Additional urine aliquots $(20 \mathrm{~mL})$ were stored at $-20^{\circ} \mathrm{C}$ for later measurement of 8 -OHdG.

\section{Composite heavy metal exposure}

Urine samples were analyzed for the following heavy metals: aluminium, arsenic, cadmium, lead, mercury, nickel and beryllium by using an inductively coupled argon plasma mass spectrometry (ICPMS) with an Agilent 7500ce instrument as described elsewhere [24]. According to the IUPAC guideline the reference value was defined within the $95 \%$ confidence interval of the $95^{\text {th }}$ population percentile [25]. The results in the samples were expressed as $\mu \mathrm{g} / \mathrm{L}$. As already suggested by Pizzino et al. [26] in order to express the Composite Exposure Index, a Principal Component Analysis was performed and the resulted F1 factor was assumed as representative of global exposure to all other heavy metals. Correlation and linear regression were calculated according to Spearman's method or Pearson's test, for nonparametric or parametric data, respectively.

\section{Faecal ammonia analysis}

Faecal samples were placed on dry ice and immediately taken to the laboratory where they were quickly thawed in a warm water bath $\left(30^{\circ} \mathrm{C}\right)$ and homogenized and aliquots kept frozen at $-70^{\circ} \mathrm{C}$. After faeces were diluted and centrifuged, ammonia concentration was measured as follows. The stool was suspended in $0.02 \mathrm{~N} \mathrm{HCl}$ and heated at $100^{\circ} \mathrm{C}$ for $1 \mathrm{~h}$. The supernatant obtained from centrifugation of the solution (18000 x G, $10 \mathrm{~min}$ ) was filtered and analyzed as a sample for ammonia level quantification using HPLC.

\section{Faecal analysis of oxidative stress}

To assess the in vitro generation of reactive oxygen species in the morning faeces, the slightly modified method based on dimethyl sulfoxide-methanesulfinic acid reaction was used [22]. Each fecal sample
(1-2 g) was incubated for $5 \mathrm{~h}$ at $37^{\circ} \mathrm{C}$ in tris-buffered saline ( $\left.\mathrm{pH} 7.0\right)$ containing $5 \%$ dimethyl sulfoxide as a scavenger for hydroxyl radicals $(0.7 \mathrm{~mol} / \mathrm{L})$, glucose $(0.1 \%)$ and Na2EDTA $(50 \mathrm{mmol} / \mathrm{L})$ at $37^{\circ} \mathrm{C}$. The sample was then centrifuged at $900 \times g$ for $10 \mathrm{~min}$ at room temperature. Then, by lowering the $\mathrm{pH}$ to 1.0 for $10 \mathrm{~min}$ with the addition of 12 $\mathrm{mol} \mathrm{HCl} / \mathrm{L}$, the supernatant was separated and the protein removed as a precipitate. The sample, returned to 7.4 , was centrifuged at $900 \times$ $g$ for $10 \mathrm{~min}$ at room temperature and the supernatant was stored at $-20^{\circ} \mathrm{C}$ before analysis of the methane sulfinic acid content. The control sample contained deferoxamin to avoid the catalytical conversion of superoxide to the hydroxyl radical. After the reaction was halted with $500 \mu \mathrm{L}$ deferoxamin $(15 \mathrm{mmol} / \mathrm{L})$, methane sulfinic acid was extracted and analyzed by straight phase HPLC to determine methane sulfinic acid. All samples were measured in triplicate.

\section{Faecal heavy metal test}

A $15 \mathrm{mg}$ of stool specimen was used to perform this analysis by using the same ICP-MS methodology as the one above described for urine. Data were expressed on a dry weight basis to avoid variability related to water content of the specimen

\section{8-OHdG urinary concentration}

Urinary 8-OHdG concentrations were measured using an enzymelinked immunosorbent assay (8-Hydroxydeoxyguanosine Check; Japan Institute for the Control of Aging, Shizuoka, Japan) [27]. Results were expressed as ratios to the creatinine contents (per mg Cr) measured in the same samples. Optical density of each sample was tested at $490 \mathrm{~nm}$ and compared to a standard curve to measure the final concentration, as suggested by Roberts and Francetic [28].

\section{Statistical Analysis}

Data were tested for normal distribution with the Shapiro-Wilk normality test, and variables that did not display normal distribution were log-transformed. All values were expressed as mean $\pm \mathrm{SE}$. Differences in each variable among treatment groups were tested with generalized linear models adjusted for a linear response, including the three treatments and their interaction as fixed factors. The results were evaluated by one way Analysis of Variance (ANOVA) followed by a Tukey's multiple comparison test. Statistically significant differences between groups were defined as $P<0.05$. All calculations were performed with the GraphPad Prismprogram 5.0 (GraphPad Software Inc., San Diego, USA).

\section{Results}

No adverse effect was reported by any of the treatment employed. After the first month of treatment, the group given i.v. GSH had a number of voluntary drop out or skipping the appointment (altogether 10 subjects) thus making the second month data unavailable for statistical analysis per se. Nonetheless, the remaining subjects continued the study and care was taken in order to statistically evaluate the group given treatment only for a month.

\section{Measurement of glutathione status in erythrocytes}

At baseline, all groups had a similar redox profile, While i.v. GSH showed not to exert any significant effect on the examined redox parameter, GSH-9599 showed to significantly increase RBC level of GSH and of GPx and a reduction of GSSG already at 1-month observation and throughout the study period (Figures 1(a,b) and 2, $\mathrm{p}<0.01)$. Chelator administration didn't bring about any modification, besides a not significant trend improvement of GSH/GSSG ratio at 2-month observation. 
Citation: Makida Y, He F, Mohania D, Balieiro-Neto G, Alagozlu H, et al. (2016) Effect of a Novel GSH-based Compound and Chabasite-phillipsitebased Chelator in Environmentally-exposed Poor Detoxifiers: An Adjuvant Hepatoprotective Treatment for Poly-drug Users? Metabolomics (Los Angel) 6: 185. doi: 10.4172/2153-0769.1000185

Page 4 of 7

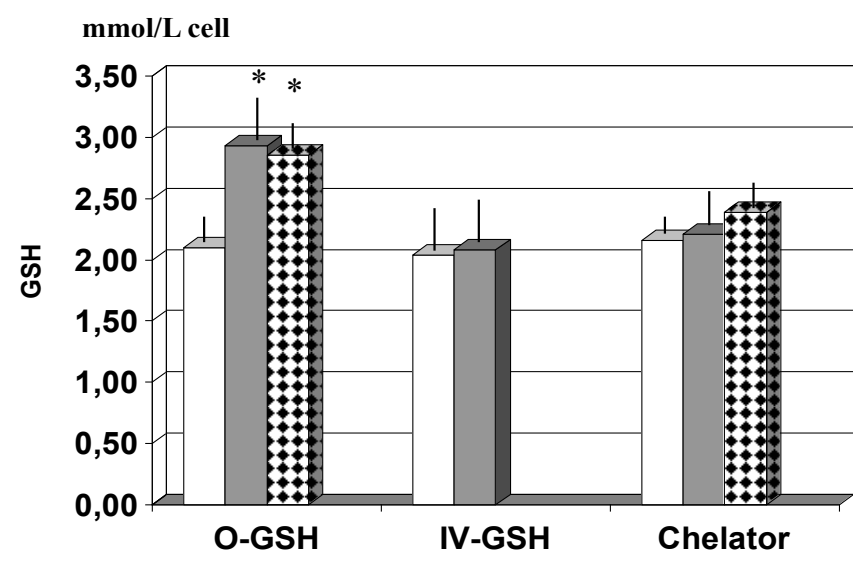

Figure 1a: Glutathione status in erythrocytes: GSH. Effect of oral, i.v. GSH or chelator. Y axis expresses GSH as $\mathrm{mmol} / \mathrm{L}$ cell. White bar: baseline; grey bar: 1-month treatment; dotted bar: 2 -month treatment. ${ }^{*} p<0.01$ vs. baseline and the other treatment groups.

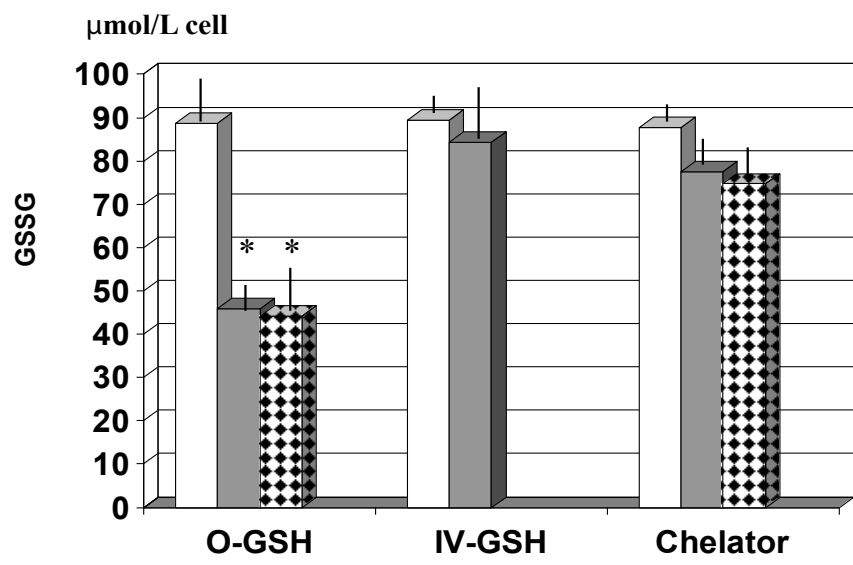

Figure 1b: Glutathione status in erythrocytes: GSSG. Effect of oral, i.v. GSH or chelator. Y axis expresses GSSG as $\mu \mathrm{mol} / L$ cell. White bar: baseline; grey bar: 1-month treatment; dotted bar: 2 -month treatment. ${ }^{*} p<0.01$ vs. baseline and the other treatment groups.

\section{U/mg Hb}

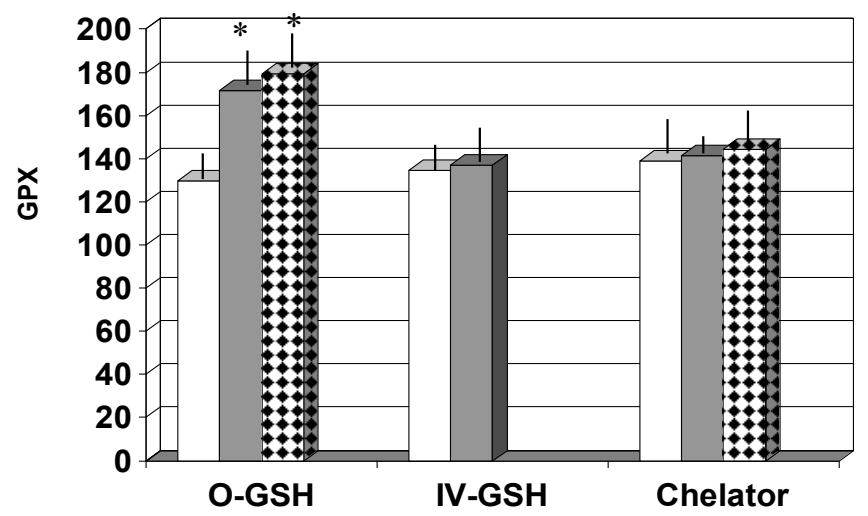

Figure 2: Glutathione status in erythrocytes: GPx. Effect of oral, i.v. GSH or chelator. $\mathrm{Y}$ axis expresses GPx as $\mathrm{U} / \mathrm{mgHb}$. White bar: baseline; grey bar: 1 -month treatment; dotted bar: 2 -month treatment. ${ }^{*} p<0.01$ vs. baseline and the other treatment groups.

\section{Faecal ammonia analysis}

This analysis showed that neither GLU-9599 nor i.v. GSH administration changed the gut extraction of ammonia. On the other hand, the oral Chabasite-phillipsite-based chelator brought about a significantly decreased concentration already at 1-month observation $(\mathrm{p}<0.001$ vs. baseline) and this effect was maintained also at the end of the study (Figure 3, $\mathrm{p}<0.001$ ).

\section{Faecal analysis of oxidative stress}

Gut epithelial oxidative stress was not affected by GLU-9599 or i.v. GSH but decreased in the chelator-treated group and this reached a statistically significant level only at the end of the study (Figure 4, $\mathrm{p}<0.01$ vs. baseline).

\section{Faecal heavy metal test}

Irrespective of the group, all patients showed an overall abnormal faecal metals profile with the exception of antimonium and nickel. Unlike i.v. GSH, GSH-9599 brought about a trend increase of cadmium elimination by faeces but this didn't reach a statistical significance (Table 1). On the other hand, the chelator-treated group showed a significant faecal elimination of heavy metals starting at 1-month observation (Table 1, $\mathrm{p}<0.05$ vs. baseline) and with a further timecourse trend increase at the end of the study as for mercury, cadmium and lead.

\section{8-OHdG urinary concentration and correlation with Composite Heavy Metal Exposure}

Subjects showed a wide range of urinary concentration of 8-OHdG at baseline (Figure 5). Although i.v. GSH seemed to bring about a trend decrease of this value, this did not reach a statistical significance. However, GSH-9599-treated group showed a significant decrease of this parameter already after one month (Figure 6, p <0.05) and this effect was maintained also at the end of the study ( $p<0.05$ vs. baseline). The chelator administration didn't modify this parameter. When plotting this scattered figure against composite heavy metal exposure, it appeared to be a significant direct relationship among the two variable with a linear regression pattern (Figure 6, r: 0.63, p<0.05). No other baseline variable, either anthropometric, biochemical or gender showed a significant correlation with composite heavy metal exposure.

\section{Discussion}

The liver carries almost a complete array of drug metabolizing enzymes and the majority of them detoxify xenobiotics or endobiotics. However, in some instances, these mechanisms aren't totally efficient or overburdened by toxins and this leads to an accumulation of metabolites with potential liver injury and/or activation of systemic chronic inflammation [29]. Exposure in daily life to varying doses of environmental contaminants and toxicants has been related to human health and depends also on individual genetic susceptibility to xenobiotic metabolism. These range from subjects with regular detoxification enzymatic functions to poor metabolizers showing from low to no specific enzyme activity [20]. Although phase I detoxification study was outside the aim of our study, it is noteworthy mentioning that Cytochrome monooxygenases P450 enzymes (CYPs) mediated drugs bioactivation may trigger harmful oxidative stress and indeed CYPs are the main source of ROS [30]. As a matter of fact, CYP1A1 phase I enzyme, and GSTM1 phase II enzyme, could significantly affect individual variability in the metabolism of chemical substances and finally modifying the susceptibility also to cancers [31-33]. This is because glutathione-S-transferase acts in the detoxification of 
Citation: Makida Y, He F, Mohania D, Balieiro-Neto G, Alagozlu H, et al. (2016) Effect of a Novel GSH-based Compound and Chabasite-phillipsitebased Chelator in Environmentally-exposed Poor Detoxifiers: An Adjuvant Hepatoprotective Treatment for Poly-drug Users? Metabolomics (Los Angel) 6: 185. doi: 10.4172/2153-0769.1000185

Page 5 of 7

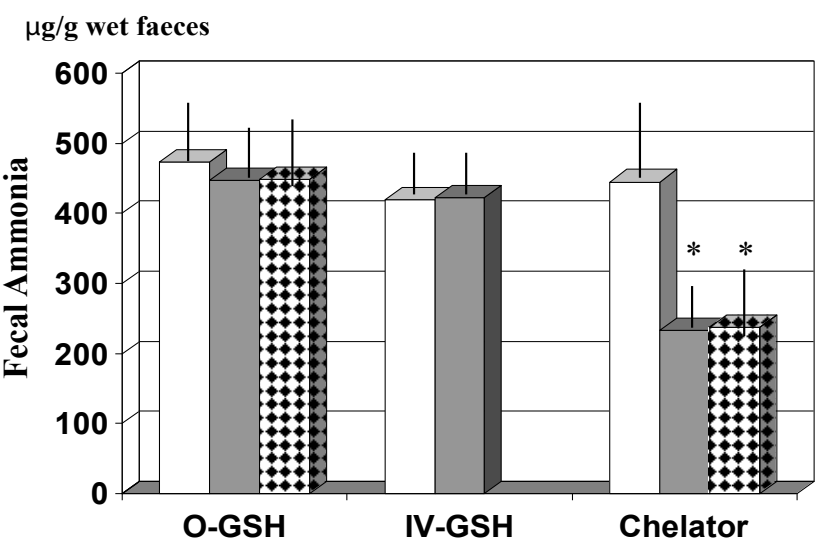

Figure 3: Faecal ammonia analysis ( $\mu \mathrm{g} / \mathrm{g}$ wet faeces). Effect of oral, i.v. GSH or chelator. White bar: baseline; grey bar: 1-month treatment; dotted bar: 2-month treatment. ${ }^{*} p<0.001$ vs. baseline and the other treatment groups.

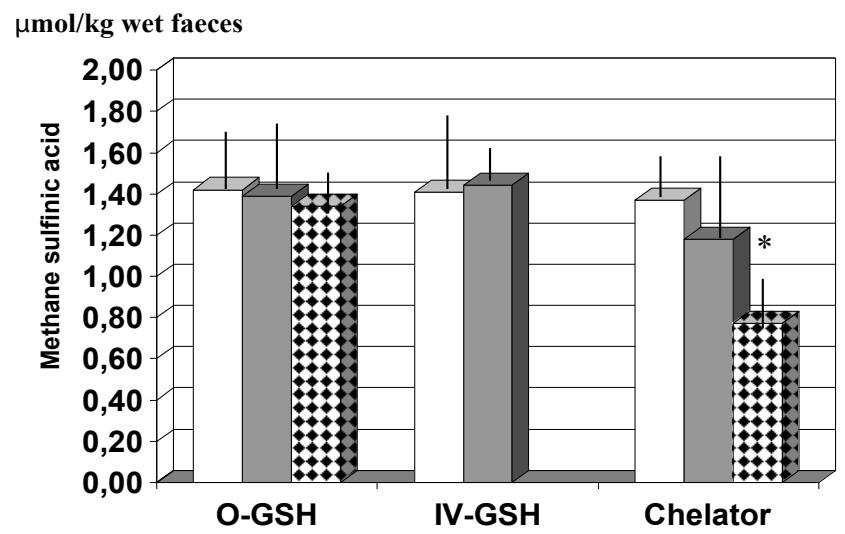

Figure 4: Faecal analysis of oxidative stress. Effect of oral, i.v. GSH or chelator Expressed as Methane sulfinic acid. White bar: baseline; grey bar: 1-month treatment; dotted bar: 2 -month treatment. ${ }^{*} p<0.01$ vs. baseline and the other treatment groups.

xenobiotics, drugs and toxins and metabolites are also involved in the regulation of mitogen-activated protein kinases [34,35]. Interestingly, our subjects, as pre-selected to be GSTM-1 null genotype, had a normal erythrocyte redox balance but a rather wide distribution of urinary 8-OHdG comprising up to significantly abnormal values. 8-OHdG urinary concentration is one of the most relevant effects of free radicalinduced oxidative lesions in DNA structure. This biomarker has been also used to evaluate DNA damage in humans after exposure to mutagenic agents, such as tobacco smoke, hydrocarbons derivatives and heavy metals which are known indeed to generate reactive oxygen species either in humans and inside the ecosystem [36-39]. In this respect, our study confirmed prior observations about a significant direct correlation between urinary concentration of 8 -OHdG and composite heavy metal exposure [26]. It is noteworthy that chelator was the only treatment to significantly increase stool discharge of heavy metal (xenotoxin) and ammonia (endotoxin) and, at the same time, decreasing gastrointestinal oxidative stress. The importance to lower endotoxin has already been shown in healthy individuals doing intense physical activity [19]. However, this treatment did not affect redox balance when measured at RBC level and urinary concentration of 8-OHdG which. We have no sound explanation for this discrepancy but we have to consider that chelators act through sieving physical cation-exchange mechanisms exclusively at gut level (Figure 7) with potential osmotic retrieval of heavy metal from the body. This explains the increased stool discharge of pollutants during treatment with chelators but, on the other hand, a direct and significant systemic redox regulating effect cannot be expected. Faecal biliary excretion is the main elimination route of many toxic metals from the body, thus representing a fairly reliable indicator of dietary exposure. Considering that the formation of metal-glutathione complexes, $90 \%$ of which are excreted into the bile, is the most important process by which sulfhydryl reactive metals are eliminated, one cannot rule out the possibility that the association of chelators could benefit from the addition of viable sources of GSH, such as GLU-9599 seems to offer. As a matter of fact, unlike i.v. infusion of GSH, GLU-9599 significantly improved the urinary excretion of $8-\mathrm{OHdG}$ which, as outlined above, was correlated to the composite exposure index, i.e., a validated cumulative parameter evaluating appropriate aggregation of indicators which are representative of the whole dynamic phenomenon [40].

\begin{tabular}{|c|c|c|c|c|}
\hline & $\begin{array}{c}\text { Normal } \\
\text { range }\end{array}$ & Glu-9599 & IV-GSH & Chelator \\
\hline $\begin{array}{r}\text { Mercury } \\
\mathrm{mg} / \mathrm{kg} \text { dry wt }\end{array}$ & $<0.5$ & $\begin{array}{c}(1.1 \pm 0.4) \\
0.9 \pm 0.5 \\
1.0 \pm 0.6\end{array}$ & $\begin{array}{c}(0.9 \pm 0.3) \\
0.9 \pm 0.6\end{array}$ & $\begin{array}{c}(1.0 \pm 0.4) \\
1.4 \pm 0.2^{*} \\
1.5 \pm 0.6^{*}\end{array}$ \\
\hline $\begin{array}{l}\text { Cadmium } \\
\mathrm{mg} / \mathrm{kg} \text { dry wt }\end{array}$ & $<0.5$ & $\begin{array}{c}(1.2 \pm 0.4) \\
1.1 \pm 0.5 \\
1.3 \pm 0.5\end{array}$ & $\begin{array}{c}(1.0 \pm 0.3) \\
1.1 \pm 0.5\end{array}$ & $\begin{array}{c}(1.1 \pm 0.2) \\
1.4 \pm 0.1^{*} \\
1.5 \pm 0.7^{*}\end{array}$ \\
\hline $\begin{array}{c}\text { Lead } \\
\mathrm{mg} / \mathrm{kg} \text { dry wt }\end{array}$ & $<0.5$ & $\begin{array}{l}(0.7 \pm 0.1) \\
0.8 \pm 0.3 \\
0.7 \pm 0.6\end{array}$ & $\begin{array}{c}(0.8 \pm 0.12) \\
0.8 \pm 0.09\end{array}$ & $\begin{array}{c}(0.7 \pm 0.08) \\
1.2 \pm 0.45^{\star} \\
1.3 \pm 0.11^{* *}\end{array}$ \\
\hline $\begin{array}{l}\text { Arsenicum } \\
\mathrm{mg} / \mathrm{kg} \text { dry wt }\end{array}$ & $<0.3$ & $\begin{array}{l}(0.7 \pm 0.09) \\
0.08 \pm 0.027 \\
0.07 \pm 0.043\end{array}$ & $\begin{array}{l}(0.6 \pm 0.1) \\
0.6 \pm 0.08\end{array}$ & $\begin{array}{l}(0.8 \pm 0.1) \\
1.4 \pm 0.07^{*} \\
1.3 \pm 0.14^{*}\end{array}$ \\
\hline $\begin{array}{l}\text { Antimonium mg/ } \\
\mathrm{kg} \text { dry wt }\end{array}$ & $<0.08$ & $\begin{array}{c}(0.06 \pm 0.01) \\
0.05 \pm 0.01 \\
0.06 \pm 0.06\end{array}$ & $\begin{array}{c}(0.04 \pm 0.03) \\
0.04 \pm 0.02\end{array}$ & $\begin{array}{c}(0.04 \pm 0.02) \\
0.04 \pm 0.01 \\
0.05 \pm 0.09\end{array}$ \\
\hline $\begin{array}{l}\text { Beryllium } \\
\mathrm{mg} / \mathrm{kg} \text { dry wt }\end{array}$ & $<0.009$ & $\begin{array}{l}(0.01 \pm 0.003) \\
0.009 \pm 0.006 \\
0.009 \pm 0.004\end{array}$ & $\begin{array}{c}(0.007 \pm \\
0.004) \\
0.007 \pm 0.002\end{array}$ & $\begin{array}{c}(0.009 \pm 0.004) \\
0.013 \pm 0.001^{*} \\
0.015 \pm 0.002^{*}\end{array}$ \\
\hline $\begin{array}{r}\text { Nickel } \\
\mathrm{mg} / \mathrm{kg} \text { drywt }\end{array}$ & $<8$ & $\begin{array}{c}(5.8 \pm 0.8) \\
5.3 \pm 0.8 \\
5.6 \pm 0.3\end{array}$ & $\begin{array}{c}(6.4 \pm 1.2) \\
6.2 \pm 1.1\end{array}$ & $\begin{array}{c}(6.1 \pm 0.16) \\
5.6 \pm 0.36 \\
5.4 \pm 0.23\end{array}$ \\
\hline
\end{tabular}

Table 1: Faecal heavy metal test: effect of oral, i.v. GSH or chelator. 1: Values at 1 -month observation in brackets. 2 : values at 2 -month observation. $p<0.01$ vs baseline and the other treatment groups.

ng/g creatinine

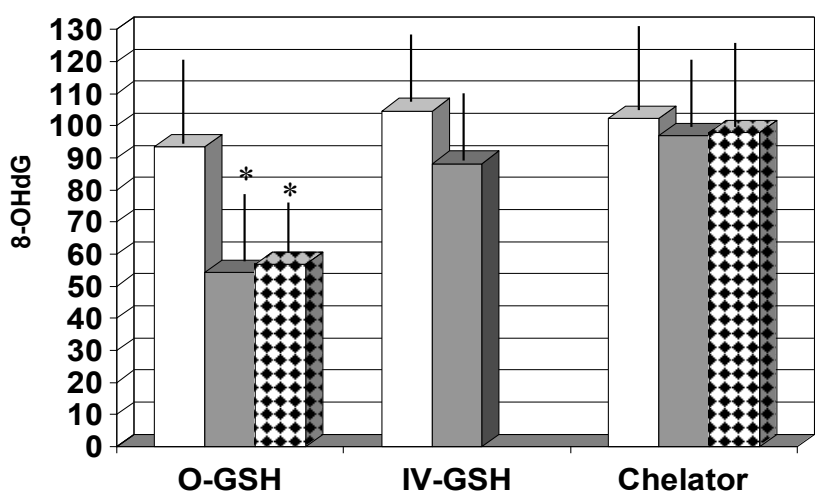

Figure 5: Effect of oral, i.v. GSH or chelator on 8-OHdG urinary concentration. White bar: baseline; grey bar: 1-month treatment; dotted bar: 2-month treatment. ${ }^{*} p<0.01$ vs. baseline and the other treatment groups. 
Citation: Makida Y, He F, Mohania D, Balieiro-Neto G, Alagozlu H, et al. (2016) Effect of a Novel GSH-based Compound and Chabasite-phillipsitebased Chelator in Environmentally-exposed Poor Detoxifiers: An Adjuvant Hepatoprotective Treatment for Poly-drug Users? Metabolomics (Los Angel) 6: 185. doi: 10.4172/2153-0769.1000185

Page 6 of 7

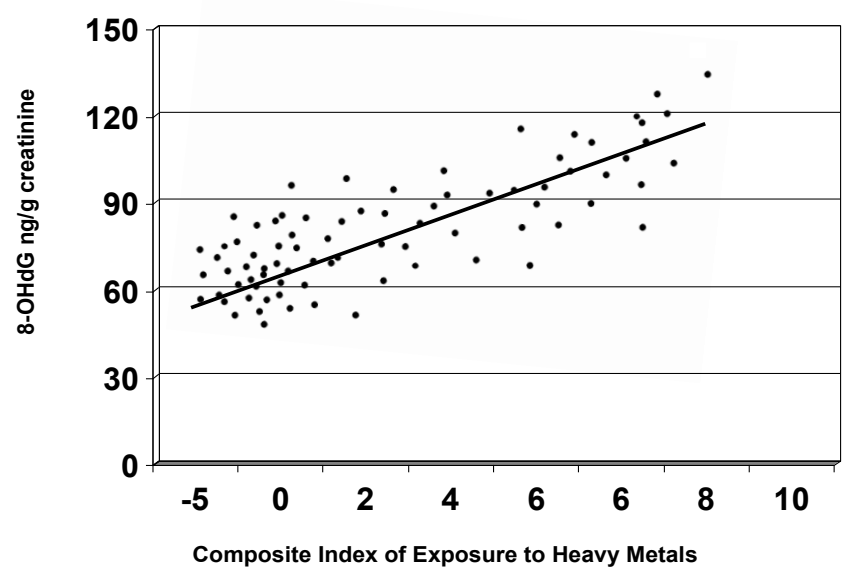

Figure 6: 8-OHdG urinary concentration plotted against composite heavy metal exposure. ${ }^{*} p<0.01 \mathrm{vs}$. baseline.

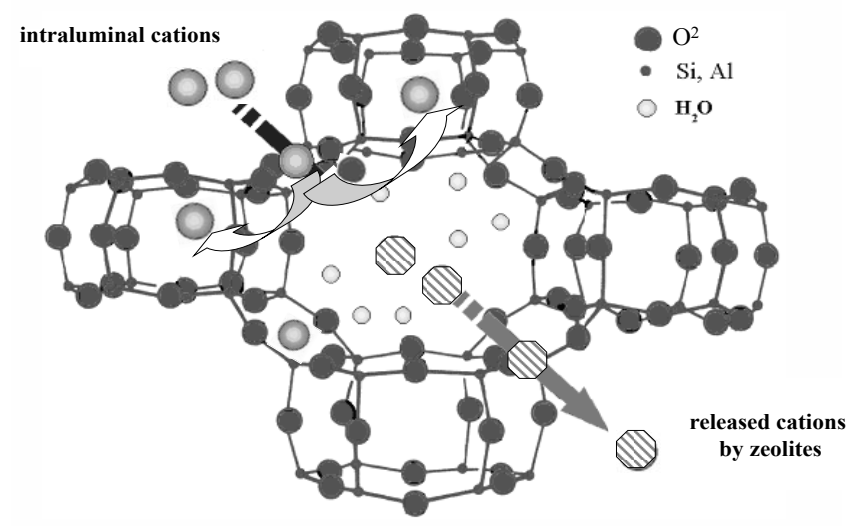

Figure 7: Schematic representation of cation exchange process within specia zeolites. In the figure, one (beneficial) cation is discharged into the lumen while 2 intraluminal cations are attracted and trapped inside.

One can envisage that Glu-9599, although unaffecting heavy metals discharge per se, may have beneficially influenced the related oxidative stress caused by pollutants at a systemic level. The quest to orally deliver viable GSH until recently has been rather disappointing and recently Allen and Bradley RD by testing an oral GSH-based supplement in healthy humans showed that this brought about no significant changes in biomarkers of oxidative stress, including glutathione status [41].

This holds of interest when considering the recent findings of $\mathrm{Al}$ Bakheet et al. [42] who pointed out that, under pollutant exposure, the mRNA expression levels of detoxifying genes such as also GSTM-1 were significantly decreased and affecting also CYP1A1 which regulates key enzymes in drug, xenobiotic metabolism and procarcinogens inactivation. In summary, the widespread environmental concern and of poly-pharmacological regimes pose a constant threat to health and this may particularly apply to poor-detoxifier individuals. Thus, this formulation of orobuccal fast release GSH stabilized in food grade fat matrix and capable of delivering native reduced glutathione may represent a valuable adjuvant therapeutic option.

\section{References}

1. Betton GR (2013) A review of the toxicology and pathology of the gastrointestinal tract. Cell Biol Toxicol 29: 321-338.
2. Greig J, Thurtle N, Cooney L, Ariti C, Ahmed AO, et al. (2014) Association of blood lead level with neurological features in 972 children affected by an acute severe lead poisoning outbreak in Zamfara State, northern Nigeria. PLoS One 9: e93716

3. García-Esquinas E, Navas-Acien A, Pérez-Gómez B, Artalejo FR (2015) Association of lead and cadmium exposure with frailty in US older adults. Environ Res 137: 424-431.

4. Ponce E, Aquino NB, Louie MC (2013) Chronic cadmium exposure stimulates SDF-1 expression in an ER $\alpha$ dependent manner. PLoS One 8: e72639.

5. Yuan D, Ye S, Pan Y, Bao Y, Chen H, et al. (2013) Long-term cadmium exposure leads to the enhancement of lymphocyte proliferation via downregulating p16 by DNA hypermethylation. Mutat Res 757: 125-131.

6. Elmgren R (2001) Understanding human impact on the Baltic ecosystem: changing views in recent decades. Ambio 30: 222-231.

7. Langie SA, Koppen G, Desaulniers D, Al-Mulla F, Al-Temaimi R, et al. (2015) Causes of genome instability: the effect of low dose chemical exposures in modern society. Carcinogenesis: S61-S88.

8. Wang T, Feng W, Kuang D, Deng Q, Zhang W, et al. (2015) The effects of heavy metals and their interactions with polycyclic aromatic hydrocarbons on the oxidative stress among coke-oven workers. Environ Res 140: 405-413.

9. Ogawa M, Kayama F (2015) A study of the association between urinary aluminum concentration and pre-clinical findings among aluminum-handling and non-handling workers. J Occup Med Toxicol 10: 13.

10. Li P, Gu Y, Yu S, Li Y, Yang J, et al. (2014) Assessing the suitability of 8-OHdG and micronuclei as genotoxic biomarkers in chromate-exposed workers: a cross-sectional study. BMJ Open 4: e005979.

11. Quiñones L, Berthou F, Varela N, Simon B, Gil L, et al. (1999) Ethnic susceptibility to lung cancer: differences in CYP2E1, CYP1A1 and GSTM1 genetic polymorphisms between French Caucasian and Chilean populations. Cancer Lett 141: 167-171.

12. Sirivarasai J, Wananukul W, Kaojarern S, Chanprasertyothin S, Thongmung $\mathrm{N}$, et al. (2013) Association between inflammatory marker, environmental lead exposure, and glutathione S-transferase gene. Biomed Res Int 474963.

13. Barcelos GR, Souza MF, Oliveira AÁ, Lengert AV, Oliveira MT, et al. (2015) Effects of genetic polymorphisms on antioxidant status and concentrations of the metals in the blood of riverside Amazonian communities co-exposed to $\mathrm{Hg}$ and $\mathrm{Pb}$. Environ Res 138: 224-232.

14. de Oliveira AÁ, de Souza MF, Lengert AV, de Oliveira MT, Camargo RB, et al. (2014) Genetic polymorphisms in glutathione (GSH-) related genes affect the plasmatic $\mathrm{Hg}$ /whole blood $\mathrm{Hg}$ partitioning and the distribution between inorganic and methylmercury levels in plasma collected from a fish-eating population. Biomed Res Int 2014: 940952

15. Dey T, Gogoi K, Unni BG, Kalita M, Bharadwaz M, et al. (2014) Role of glutathione $\mathrm{S}$ transferase polymorphism in COPD with special reference to peoples living in the vicinity of the open cast coal mine of Assam. PLoS One 9: e96739.

16. Horska A, Mislanova C, Bonassi S, Ceppi M, Volkovova K, et al. (2011) levels in blood are influenced by polymorphisms in glutathione S-transferases. Eur J Nutr 50: 437-446.

17. Sheasgreen C, Lu L, Patel A (2014) Pathophysiology, diagnosis, and management of hepatic encephalopathy. Inflammopharmacology 22: 319-326.

18. De Preter V, Vanhoutte T, Huys G, Swings J, De Vuyst L, et al. (2007) Effects of Lactobacillus casei Shirota, Bifidobacterium breve, and oligofructose-enriched inulin on colonic nitrogen-protein metabolism in healthy humans. Am J Physio Gastrointest Liver Physiol 292: G358-G368.

19. Nybo L, Dalsgaard MK, Steensberg A, Møller K, Secher NH (2005) Cerebra ammonia uptake and accumulation during prolonged exercise in humans. J Physiol 563: 285-290.

20. Bolt HM, Thier R (2006) Relevance of the deletion polymorphisms of the glutathione S-transferases GSTT1 and GSTM1 in pharmacology and toxicology. Curr Drug Metab 7: 613-628.

21. Subar AF, Thompson FE, Kipnis V, Midthune D, Hurwitz P, et al. (2001) Comparative validation of the Block, Willett, and National Cancer Institute food frequency questionnaires: the Eating at America's Table Study. Am J Epidemiol 154: 1089-1099. 
Citation: Makida Y, He F, Mohania D, Balieiro-Neto G, Alagozlu H, et al. (2016) Effect of a Novel GSH-based Compound and Chabasite-phillipsitebased Chelator in Environmentally-exposed Poor Detoxifiers: An Adjuvant Hepatoprotective Treatment for Poly-drug Users? Metabolomics (Los Angel) 6: 185. doi: 10.4172/2153-0769.1000185

22. Rahman I, Kode A, Biswas SK (2006) Assay for quantitative determination of glutathione and glutathione disulfide levels using enzymatic recycling method. Nat Protoc 1: 3159-3165

23. Steiner MG, Babbs CF (1990) Quantitation of the hydroxyl radical by reaction with dimethyl sulfoxide. Arch Biochem Biophys 278: 478-481.

24. Banza CLN, Nawrot TS, Haufroid V, Decrée S, De Putter T, et al. (2009) High human exposure to cobalt and other metals in Katanga, a mining area of the Democratic Republic of Congo. Environ Res 109: 745-752.

25. Cornelis R, Fuentes-Arderiu X, Bruunshuus I, Templeton D (1997) Internationa Union of Pure and Applied Chemistry and International Federation of Clinical Chemistry, Committee on Nomenclature. Properties and Units (C-NPU): properties and units in the clinical laboratory sciences. IX. Properties and units in trace elements (IFCC-IUPAC technical report 1997). Eur J Clin Chem Clin Biochem 35: 833-843.

26. Pizzino G, Bitto A, Interdonato M, Galfo F, Irrera N, et al. (2014) Oxidative stress and DNA repair and detoxification gene expression in adolescents exposed to heavy metals living in the Milazzo-Valle del Mela area (Sicily, Italy). Redox Biol 2: 686-693.

27. Saito S, Yamauchi H, Hasui Y, Kurashige J, Ochi H, et al. (2000) Quantitative determination of urinary 8-hydroxydeoxyguanosine (8-OHdG) by using ELISA Res Commun Mol Pathol Pharmacol 107: 39-44.

28. Roberts JC, Francetic DJ (1993) The importance of sample preparation and storage in glutathione analysis. Anal Biochem 211: 183-187.

29. Woolbright BL, Jaeschke H (2015) Xenobiotic and Endobiotic Mediated Interactions Between the Cytochrome P450 System and the Inflammatory Response in the Liver. Adv Pharmacol 74: 131-161.

30. Bhattacharyya S, Sinha K, Sil PC (2014) Cytochrome P450s: mechanisms and biological implications in drug metabolism and its interaction with oxidative stress. Curr Drug Metab 15: 719-742.

31. Nebert DW, McKinnon RA, Puga A (1996) Human drug-metabolizing enzyme polymorphisms: effects on risk of toxicity and cancer. DNA Cell Biol 15: 273-280.
32. Gonzalez FJ (1997) The role of carcinogen-metabolizing enzyme polymorphisms in cancer susceptibility. Reprod Toxicol 11: 397-412.

33. Moon KS, Lee HJ, Hong SH, Kim HM, Um JY, et al. (2007) CYP1A1 and GSTM1/T1 genetic variation in predicting risk for cerebral infarction. J Mo Neurosci 32: 155-159.

34. Salinas-Souza C, Petrilli AS, de Toledo SR (2010) Glutathione S-transferase polymorphisms in osteosarcoma patients. Pharmacogenet Genomics 20: 507-515.

35. Liu H, Jia J, Mao X, Lin Z (2015) Association of CYP1A1 and GSTM1 Polymorphisms with oral Cancer susceptibility: A meta-analysis. Medicine (Baltimore) 94: e895

36. Yuan TH, Chung MK, Lin CY, Chen ST, Wu KY, et al. (2016) Metabolic profiling of residents in the vicinity of a petrochemical complex. Sci Total Environ 548 260-269.

37. Wu S, Bai YN, Pu HQ, He J, Zheng TZ, et al. (2015) Dynamic Changes in DNA Damage and Repair Biomarkers with Employment Length among Nickel Smelting Workers. Biomed Environ Sci 28: 679-682.

38. Lopes AC, Peixe TS, Mesas AE, Paoliello MM (2016) Lead Exposure and Oxidative Stress: A Systematic Review. Rev Environ Contam Toxicol 236: 193238.

39. Javed M, Ahmad I, Usmani N, Ahmad M (2016) Studies on biomarkers of oxidative stress and associated genotoxicity and histopathology in Channa punctatus from heavy metal polluted canal. Chemosphere 151: 210-219.

40. Lalloué B, Monnez JM, Padilla C, Kihal W, Zmirou-Navier D, et al. (2015) Data analysis techniques: a tool for cumulative exposure assessment. J Expo Sci Environ Epidemiol 25: 222-230.

41. Allen J, Bradley RD (2011) Effects of oral glutathione supplementation on systemic oxidative stress biomarkers in human volunteers. J Altern Complement Med 17: 827-833.

42. Al Bakheet SA, Attafi IM, Maayah ZH, Abd-Allah AR, Asiri YA, et al. (2013) Effect of long-term human exposure to environmental heavy metals on the expression of detoxification and DNA repair genes. Environ Pollut 181: 226-232. 